\title{
A Study of Due Recyclable Waste Containers in Taiwan
}

\author{
Wei-Lung Huang*
}

China University of Science and Technology, No. 245, Sec.3 Academia Rd., Nangang Dist., Taipei City 11581, Taiwan, R.O. China

\begin{abstract}
This study surveys the operation modes, results and problems of the waste container recycling system in Taiwan, known as the Four-in-One Program, and compares the collation and time trend analysis of the program's results (such as the garbage clearance volume, the recycling rate of recyclable resources, the price of plastic "Due Recyclable Waste Containers" (DRWCs), among other variables). The results show that the Four-in-One Program in Taiwan could prevent waste generation and increase recycling weight and that the program's key contributing factors are the collective environmental consciousness, subsidies, and the resources recycle fee (RRF). However, the decreasing trends of the daily per capita garbage clearance volume in Taiwan and Japan might be because the Four-in-One Program's municipal garbage collection teams check the trash to retrieve recyclable resources.
\end{abstract}

Keywords: Due recyclable waste containers, resources recycle fee (RRF), subsidy.

\section{INTRODUCTION}

Taiwan's Environmental Protection Administration (EPA) has classified most waste containers as "Due Recyclable Waste Containers" (DRWCs). Based on the Waste Disposal Act, the EPA has classified DRWCs into 6 groups comprising 13 categories: iron containers, aluminum containers, glass containers, paper containers (including aseptic cartons, paper cartons, and paper tableware), pesticide containers, and plastic containers. Plastic container types are: Polyethylene terephthalate (PET), Polyvinylchloride (PVC), Polyethylene (PE), Polypropylene (PP), Polystyrene (PS) form, and PS non-form.

The recycling system for DRWCs is the Four-in-One Resource Recycling Program (Four-in-One Program), which has been effectively regulated by the Recycling Fund Management Board (RFMB). Started in 1997, the Four-inOne Program combines its four players (community residents, municipal garbage collection teams, recycling enterprises and the RFMB) to establish effective recycling schemes and to provide convenient recycling channels for DRWCs. [1] showed that the Four-in-One Program, which is a market-incentive (combined product charge and subsidy policy) system, has stimulated and established the recycling market for DRWCs, provided thousands of jobs, and generated NT\$ billions of dollars in both real production value and real Gross Domestic Product (GDP) during the 1998 survey year.

This study discusses the Four-in-One Program's operation mode and results in 2010, and evaluates the program's effectiveness at preventing waste generation and increasing recycling weight. There is evidence both pro and

\footnotetext{
*Address correspondence to this author at the China University of Science and Technology, No.245, Sec.3 Academia Rd., Nangang Dist., Taipei City 11581, Taiwan, R.O. China; Tel: 02-87320876; Fax: (02) 27864501;
}

E-mail: hippoobee@yahoo.com.tw con that obligatory separation collection systems (such as the Four-in-One Program) have prevented waste generation. For example, the European Environment Agency [2] and the European Topic Centre on Resource and Waste Management [3] have indicated that the Packaging Directive might not reduce overall waste production. However, [4] used Heckman's two-step estimation and a seemingly unrelated regression method to estimate equations for garbage and recyclables, and they concluded that the combined policy of garbage pricing and collection of PET bottles might facilitate garbage reduction. [5] suggested that the Four-in-One Program's recycling of used home appliances in Taiwan should be reformed to increase its efficiency.

Some studies have indicated that the reason that obligatory separation collection systems have resulted in increased recycling weight is because the process of separating regular garbage from recyclable resources improves the collective environmental consciousness. This study focuses on the weight of DRWCs in the Four-in-One Program. For example, [4] showed that the combined policy of garbage pricing and the collection of PET bottles encourages citizens to recycle. [6] said that the Packaging Directive required the separate collection of selected packaging and materials (such as paper, glass, metals, cardboard and wood) to provide a visible waste stream for citizens. The European Union's (EU) Packaging Directive legislation set recycling weight percentage targets for each packaging material as follows: $60 \%$ for glass, $60 \%$ for paper and cardboard, $50 \%$ for metals, $22.5 \%$ for plastics and $15 \%$ for wood. The EU member countries set their legislations to exceed some of the recovery and recycling targets initially established by the Packaging Directive. For example, Italian legislation (Decree 152/06) set the same recycling targets for glass, paper, cardboard, and metals as 
those in the Packaging Directive, but the Packaging Directive's targets are lower for plastics and wood [7] ${ }^{1}$.

To understand the Four-in-One Program's effect on DRWCs, this study compares the collation and time trend analysis of the following Four-in-One Program results: the daily per capita garbage clearance volume, the weight and recycling rate of recyclable resources, the price, and the recycling and sales weights of plastic DRWCs. [8] used a time trend analysis of the United Kingdom's MSW compositions to show that there is a potential adverse effect on the efficiency of solid waste recycling operations. [9] presented the results of a historical trend analysis modeling possible future developments in materials and energy consumption until 2010, and the results indicated that improving recycling policy saves less energy than do policies aimed at reducing paper consumption and improving process technology.

Based on the above Introduction, this paper is organized as follows: Section 2 discusses the operation mode of the Four-in-One Program, Section 3 discusses the results of the Four-in-One Program, and Section 4 offers conclusions.

\section{THE OPERATION MODE OF FOUR-IN-ONE PROGRAM}

We use a material-monetary flow diagram (see Fig. 1) to illustrate how the RFMB drives the Four-in-One Program (by means of the resources recycle fee (RRF), subsidies, auditing, certification, etc.) and its flow of money and materials (recyclable materials and waste) from one player to another.

Taiwan's resource recycling policy has been systematically implemented by the RFMB whose current practices for waste treatments often focus on the reuse, reduction and recycling of resources. Therefore, the RFMB has established the Four-in-One Program as a beneficial mechanism for resource recycling in Taiwan. The program's goals are to sort garbage into separate collections of recyclable resources and waste and to create a completely closed-loop recycling society.

As shown in Fig. (1), there are four players in the Fourin-One Program: communities, municipal garbage collection teams, recycling enterprises and the RFMB. The community organizations and residents give or sell recyclable resources to the recycling enterprises, municipal garbage collection teams and community-based voluntary recycling organizations (e.g., schools, civil organizations and retail stores) by separating their garbage.

The municipal garbage collection teams separate and collect both waste and recyclable resources, sell recyclable resources to recycling enterprises and provide a predetermined portion (almost 30\%, as determined by local government) of the revenue from selling the collected

${ }^{1}$ Packaging Directive (The Packaging and Packaging Waste Directive (Directive 94/62/EC)) is concerned with the minimization of packaging waste material and the promotion of energy recovery, re-use and recycling of packaging. The recovery and recycling targets set by the Packaging Directive were revised in 2004 by an amending Directive (2004/12/EC). Their recovery target is $60 \%$ and their recycling target is $55 \% \sim 80 \%$. The recycling targets for each packaging material (\% on weight) set in Decree $152 / 06$ are $26 \%$ for plastics and $35 \%$ for wood. recyclable resources to the related workers or organizations. The recycling enterprises purchase recyclable resources from residents, community organizations and municipal garbage collection teams. The RFMB handles the receipt and reimbursement of the resources recycle fees which are submitted by the Designated Responsible Entities (DREs, who are the manufacturers and importers of products and containers), the establishment of the resource recycling funds and convenient recycling channels, the administration of the recycling industry, the verification of resource recycling activities, and the subsidizing and incentive mechanism of the recycling enterprises, local governments and the groups which promote resource recycling activities ${ }^{2}$.

To effectively operate the Four-in-One Program's resource recycling activities, the RFMB consists of the Review Committee (FRC), the Auditing and Certification Supervisory Committee (ACSC) and the Technical Advisory Committee (TAC) and invites government agencies, trade and industry associations, academia, technical experts, civil organizations, etc., to be members of the above committees. The FRC reviews the RRF rates, the ACSC supervises the operations and results of verification organizations, and the TAC negotiates and promotes clean-up, disposal and recycling activities ${ }^{3}$.

\section{THE RESULTS OF FOUR-IN-ONE PROGRAM}

Due to the activities of the Four-in-One Program, both the weight of recyclable resources and the recycling rate increased during the period from 2000/7 2010/3. For example, the verified total weight of annual recyclable resources collected by municipal garbage collection teams has increased with time (the maximum was 245.33 thousand tons in 2010/2 and the minimum was 40.84 thousand tons in 2000/8) as proven by the trend line in Fig. (2a). The resource recycling rate of municipal garbage collection teams has also increased with time (the maximum was $37.33 \%$ in $2009 / 7$ and the minimum was $5.99 \%$ in $2000 / 7$ ) as proven by the trend line in Fig. (2b). Thus, the daily per capita garbage clearance volume has decreased with time (the maximum was 1.06 kilogram $(\mathrm{kg})$ in 2001/12 and the minimum was $0.46 \mathrm{~kg}$ in 2009/12) as demonstrated by the trend line in Fig. (2c).

The Four-in-One Program's operation increased the recycling weights and quantities of DRWCs in the period from 1997 2009. Before the Four-in-One Program started, the recycling weights and quantities of plastic DRWCs were likely near zero, as there were no subsidies. However, no

\footnotetext{
${ }^{2}$ The chairperson of the RFMB is the minister of the EPA. The RFMB has 17 23 members. These members are made of individuals from government agencies, trade and industry associations, academia, civil organizations, as well as technical experts, all of which are appointed by the minister of the EPA (see the homepage of the RFMB).

${ }^{3}$ The chairperson of the FRC is elected among its members; the FRC has 21 members from consumer and environmental groups, academia, technical experts, government agencies, the EPA and civil organizations which are appointed by the minister of the EPA. The chairperson of the ACSC is elected among its members, the ACSC has 13 15 members from consumer and environmental groups, academia, technical experts, local governments and the EPA which are appointed by the minister of the EPA. The chairperson of the TAC is assigned by EPA minister, the number of TAC members depends on needs. The TAC members are made up professionals from various industries, academics and experts, all of which are appointed by the minister of EPA. (see the homepage of RFMB).
} 


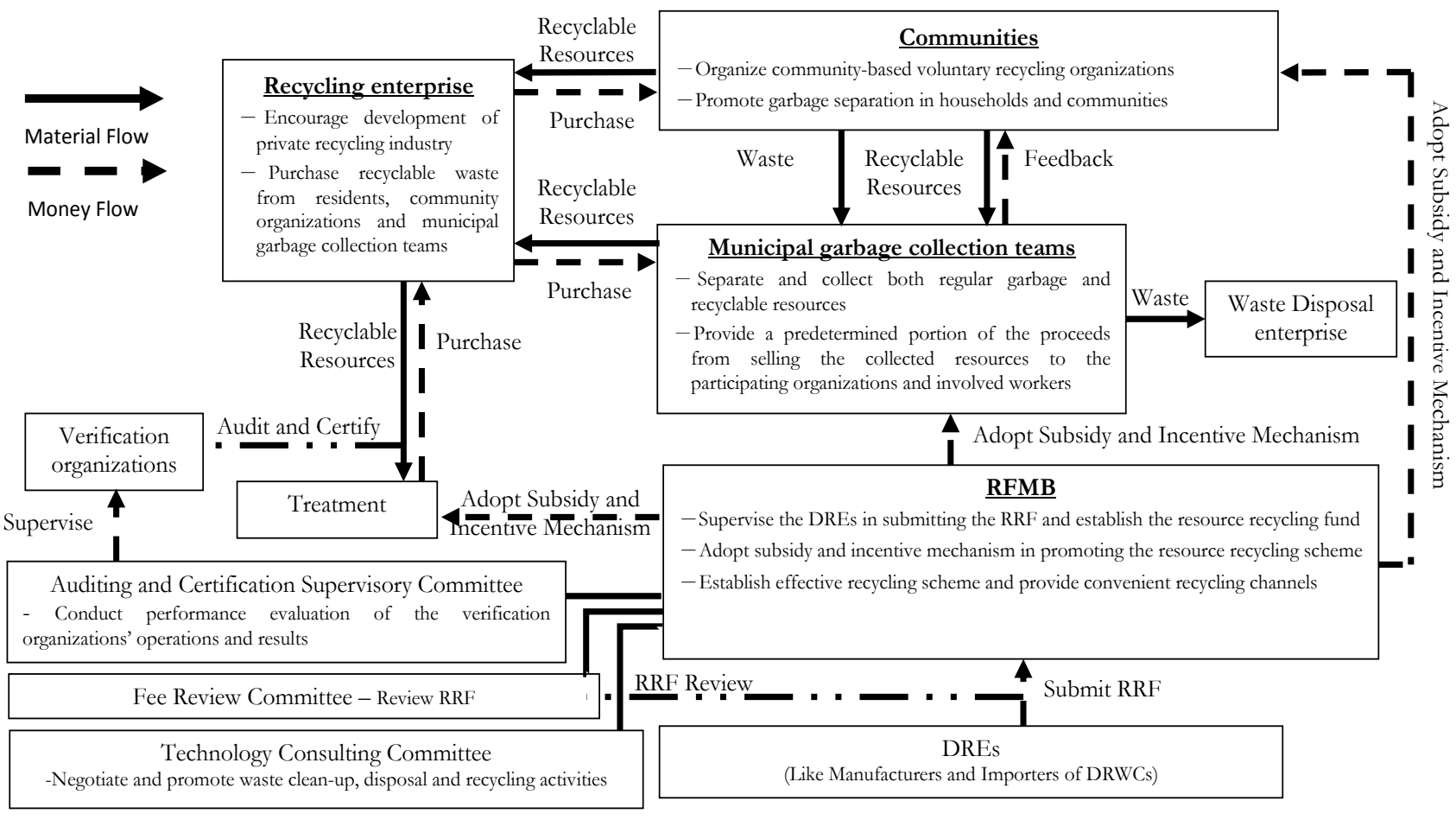

Fig. (1). The operation mode established by the four-in-one resource recycling program in Taiwan. Data source: this paper modified the homepage of RFMB.

data were collected at that time, so this paper uses statistics that became available after the program started. For example, the recycling weights and quantities of DRWCs have increased over time (the maximum was 474.77 million $\mathrm{kgs}$ in 2009 and the minimum was 19.59 million $\mathrm{kgs}$ in 1997) as shown by the trend line in Fig. (2d). Because the measuring unit of each DRWC is different, it is difficult to precisely determine the trends. However, it is evident that the recycling weights and quantities of DRWCs have increased over time.

Most countries have examples similar to those shown in Fig. (2a-d). That is, separate collection channels of recyclable resources (mainly paper, cardboard, packaging, food and garden waste, etc.) have been increasingly used to divert recyclable resources from the waste stream, and therefore the annual weight of their recyclable resources has increased year by year.

By contrast, few countries have examples similar to Fig. (2c) which shows that daily per capita garbage clearance volume has decreased year by year, and this result contradicts the conclusion of [2] and [3]. The forecast for MSW generation in the member states of the Organization for Economic Cooperation and Development (OECD) estimates that the 2025 amount will be approximately 2.2 times greater than it was in 1980 [10]. The reason for the trend shown in Fig. (2c) could be that the increment of the annual weight of recyclable resources has been greater than the increment of the annual weight of waste due to such factors as economic growth.

In the Flemish Region of Belgium, separate BMW collection in 2004 (1.30 million tons) was approximately 5.81 times greater than the collection in 1991 (0.22 million tons). However, BMW generation in 2004 increased 3.42 million tons over the amount generated in 1991 (2.20 million tons). A Decree issued on 2 July 1981 established the Public Waste Agency of Flanders (Open bare Lames Afvalstoffenmaatschappij, OVAM) and a series of waste plans. The first Waste Plan (1986 1990) initiated the separate collection of municipal waste. The second Waste Management Plan (Household Waste, 1991 1996) improved the supporting policy instruments, measures and infrastructure of the separate collection. The third Implementation Plan for Household Waste (1997 2002) established the separate collection of packaging waste and backyard composting. The target of the fourth Implementation Plan for Household Waste (2003 2007) was that $69.00 \%$ of household waste should be selectively collected and either recycled or composted. Finally, the strategy of the fifth Implementation Plan for Environmentally Responsible Household Waste Management (2008 2015) is to set up integrated management to close the cycle of selective collection, processing, reprocessing and sales (see [11-14]) ${ }^{4}$.

[15] shows that separate BMW collection in Germany in 2005 (15.60 million tons) approximated 4.35 times the collection in 1990 (3.59 million tons). Moreover, per capita BMW generation in 2005 (319 kgs), decreased from 2000 levels (367 kgs). The German state of Hesse, in cooperation with a research institution, initiated the system of separate

${ }^{4}$ The amount of BMW generation (3.42 million tons) in 2004 comes from the multiple of separate BMW collection (1.30 million tons) and the share of generated biodegradable waste collected separately (38\%). The amount of BMW generation (2.20 million tons) in 1991 comes from the multiple of separate BMW collection ( 0.22 million tons) and the share of generated biodegradable waste collected separately $(10 \%)$. 


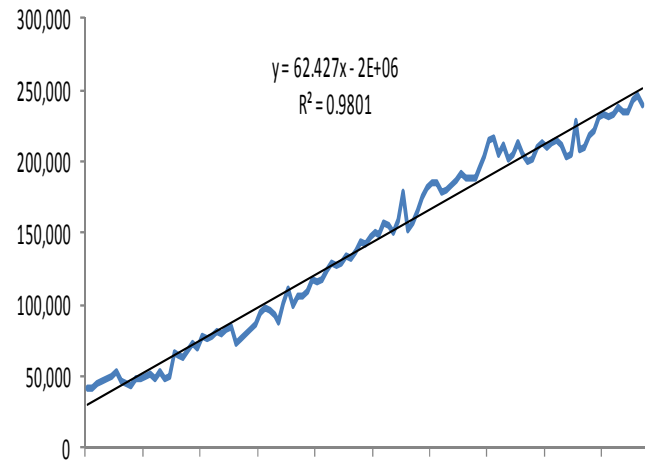

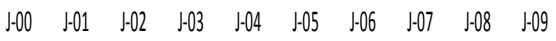

(a) The verified total weight of recyclable resources which were collected by municipal garbage collection teams (2000/7 2010/3), the unit of $\mathrm{X}$-axis is monthly data, as January of 2000 is abbreviated as $\mathrm{J}-00$, and the unit of $\mathrm{Y}$-axis is ton.

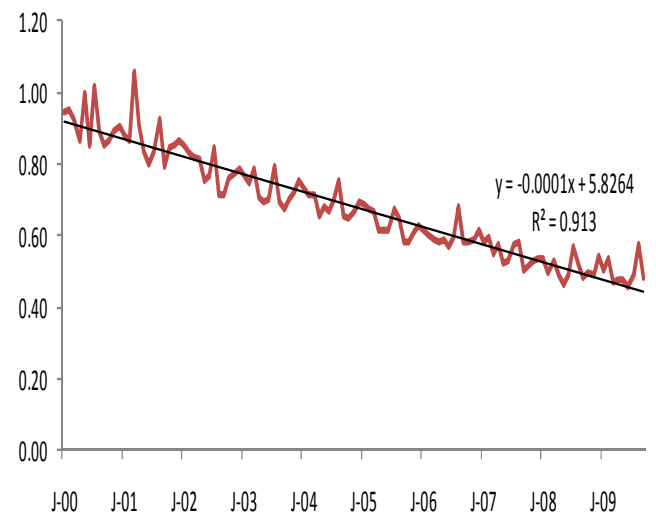

(c) The daily per capita garbage clearance volume (2000/7 2010/3), the unit of $\mathrm{X}$-axis is monthly data, and the unit of Y-axis is $\mathrm{kg}$.

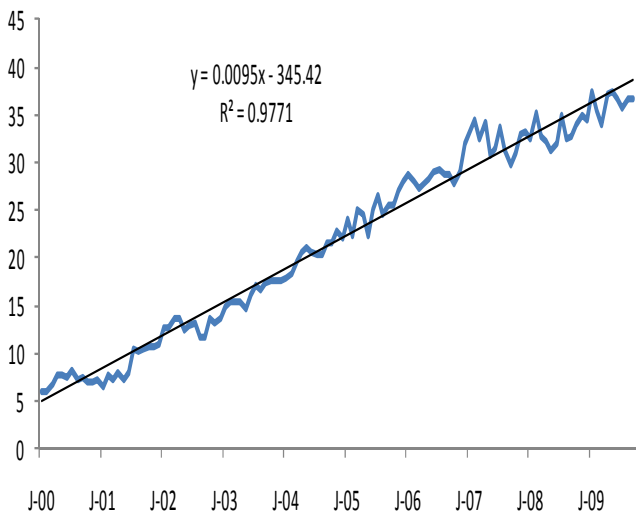

(b) The resource recycling rate of municipal garbage collection teams (2000/7 2010/3), the unit of X-axis is monthly data, and the unit of $\mathrm{Y}$-axis is \%.

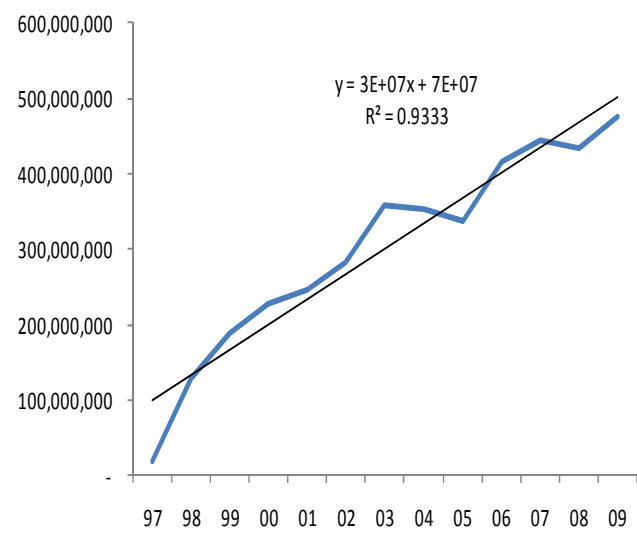

(d) The recycling weight of DRWCs (1997 2009), the unit of $X$-axis is annual data, and the unit of $\mathrm{Y}$-axis is $\mathrm{kg}$.

Fig. (2). The results of four-in-one program in Taiwan. Data source: this paper modified the data of RFMB.

BMW collection and subsequent recovery of BMWs in 1983. This system was successful, and the rest of Germany's states followed this example. Later, in 1993, the Technical Instructions on Municipal Waste (Technische Anleitung Siedlungsabfall, TASi) brought even more impetus to this system's development.

In Japan, the amount of material collected for recycling increased between 2000 (7.86 million tons) and 2008 (9.78 million tons). Meanwhile, the daily per capita generation of MSW decreased between $2000(1.185 \mathrm{~kg})$ and 2008 (1.033 $\mathrm{kg}$ ). This coincides with the initiation of the Basic Act for Establishing a Sound Material-Cycle Society (Basic Act).
The purpose of the Basic Act was to clarify the responsibilities of the State, local governments, business operators and citizens and to establish the Fundamental Plan for Establishing a Sound Material-Cycle Society. Following the plan's initiation, the concept of cyclical use (reuse, recycling and heat recovery) became popular in Japanese society (see $[16,17])$.

The reasons that the trends of daily per capita garbage clearance volume in Taiwan and Japan differ from those in the OECD might be explained by Taiwan's and Japan's perbag fee for general waste collection and disposal as well as their municipal garbage collection teams' practice of 
checking the trash to retrieve recyclable resources. On the other hand, in some OECD countries, family waste disposal fees are set according to the volume in each labeled waste bin, providing no incentive to reduce waste, and the municipal garbage collection teams do not check the trash in most countries of the OECD.

The reasons why the trends of daily per capita garbage clearance volume in Taiwan and Japan are different with OECD might be the per-bag fee collection of general waste clearance and disposal, and the municipal garbage collection teams would check the trash and collect recyclable resources in Taiwan and Japan. But family waste disposal fees are according to volume (waste bins and waste labeling) in some countries of OECD, which would have no incentive to reduce waste, and the municipal garbage collection teams would not check the trash in most countries of OECD.

Using the example of plastic DRWCs, this study proves that the recycling channels of DRWCs should become more established over time if current Four-in-One Program trends continue, as seen in Fig. (3), Appendix Fig. (1) and Appendix Fig. (2). The correlation coefficients of recycling weight $\left(r_{t}\right)$ and sales weight $\left(s_{t}\right.$ or $\left.s_{t-1}\right)$ are in the same period or lag in period $\left(\gamma\left(r_{t}, s_{t}\right)\right.$ and $\left.\gamma\left(r_{t}, s_{t-1}\right)\right)$. The increasing recycling weights and rates of Plastic DRWCs may indicate the increasing completeness of recycling channels for Plastic DRWCs in Taiwan.

As shown in Fig. (3a, b, e), the $\gamma\left(r_{t}, s_{t}\right)$ and $\gamma\left(r_{t}, s_{t-1}\right)$ of DRW PET, PVC and PP/PE containers were more than 0.30 in the period from 2003/1 2010/2. Although Fig. (3c, d) show that the $\gamma\left(r_{t}, s_{t}\right)$ and $\gamma\left(r_{t}, s_{t-1}\right)$ of DRW PS non-form and PS form containers were less than 0.30 in the period from 2003/1 2010/2, they increased in the period from 2006/1 2010/2, with 0.62 and 0.61 for DRW PS form containers and 0.24 and 0.31 for DRW PS non-form containers respectively ${ }^{5}$.

The additions of the price of the recycled materials (the recycling revenue) and their subsidies for Plastic DRWCs are near market-equilibrium magnitudes as shown by the nearly horizontal trend lines in Fig. (4a-e). This indicates that the Four-in-One Program's intended outcome of improved stability of the recycling channels has been achieved because recycling revenue should equal the difference between its cost and its normal profit in a perfectly competitive market ${ }^{6}$.

\footnotetext{
${ }^{5}$ The monthly recycling weights of DRW PET, PS non-form and PP/PE containers increased with time (the maximums were $10,493,773 \mathrm{kgs}$ in $2009 / 7,646,065 \mathrm{kgs}$ in 2008/8 and 7,837,981 $\mathrm{kgs}$ in 2009/9; the minimums were $1,708,894 \mathrm{kgs}$ in $1998 / 3,2,466 \mathrm{kgs}$ in $1999 / 2$ and $186,938 \mathrm{kgs}$ in 1998/1). This is proven by the trend line in Appendix Fig. (1a, c, e). The monthly recycling weights of DRW PVC and PS form containers decreased with time (the maximums were $1,279,817 \mathrm{kgs}$ in $1998 / 4$ and $342,761 \mathrm{kgs}$ in 2002/4; the minimums were $496 \mathrm{kgs}$ in $1998 / 11$ and 10,401 $\mathrm{kgs}$ in 2004/8). This is proven by the trend line in Appendix Fig. (1b, d). The recycling rates of PVC, PS non-form and PP/PE increased with time and the recycling rates of PET and PS form were over 100\% (see Appendix Fig. 2). Thus, the Four-in-One Program has improved the recycling results of DRW plastic containers.

${ }^{6}$ Interestingly, the recycled revenues are sometimes greater than the price of raw material, as seen in Fig. (4a, c, d). There are two possible explanations.
}

Recycled DRW PET, PS non-form and PP/PE containers fall into ranges similar to those of raw materials. The correlation coefficients of the recycled revenue $\left(P_{s, t}\right)$ and the raw material price $\left(P_{r, t}\right)$ were the same period $\left(\gamma\left(P_{s, t}, P_{r, t}\right)\right)$ for DRW PET, PS non-form containers. The PP/PE containers increased by 0.30 in the period from 2005/6 $\sim 2009 / 12$ (see Fig. 4a, c, e). On the other hand, due to the low price of raw materials, either the quality of some recycling materials was too low (as with DRW PVC containers) or the subsidies were too high (as with DRW PVC and PS form containers) to allow for improvement of recycling revenue. The $\gamma\left(P_{s, t}, P_{r, t}\right)$ of DRW PVC and PS form containers were less than 0.30 in the period from 2005/6 2009/12.

From the above discussion, it can be seen that the Fourin-One Program could prevent waste generation and increase the recycling weight of DRWCs. The program's driving factors are the raising of the collective environmental consciousness, the adoption of subsidies and incentive mechanisms to promote the resource recycling scheme, and the efforts of municipal garbage collection teams. When the subsidies and incentive mechanisms are factored in, however, the recycling revenue has always been less than the total cost of the Four-in-One Program in Taiwan. [18] compared the effectiveness of alternative policy options for 14 countries throughout Europe, Asia, North America, South America and Oceana, and found that the national programs with the highest recycling rates typically target both supply and demand through financial incentives (use-based waste management fees, deposit-refund programs, disposal taxes, etc.) that encourage source separation and recycling.

\section{CONCLUSION}

This study surveyed the mechanism and effects of Taiwan's the waste container recycling system known as the Four-in-One Program and compared the time trends of the daily per capita garbage clearance volume, the weight and recycling rate of recyclable resources, the price, and the recycling and sales weights of plastic DRWCs.

The study found that there are four players in the Fourin-One Program including communities, municipal garbage collection teams, recycling enterprises and the RFMB. The program's operating mechanism is that the municipal garbage collection teams collect and sell recyclable resources and then apportion a predetermined percentage of the resulting recycling revenue amongst the related workers and organizations.

The results showed that the Four-in-One Program in Taiwan could prevent waste generation and raise recycling weight (collective environmental consciousness) and that this phenomenon is similar to that in most countries with recycling programs. Its key factors are the improving collective environmental consciousness, the provision of subsidies, and the RRF. However, the trends of daily per capita garbage clearance volume in Taiwan and Japan are

One is that the price of recycled material is near the price of raw material. The other is that subsidies are larger than the difference between their prices of recycled material and raw material. 


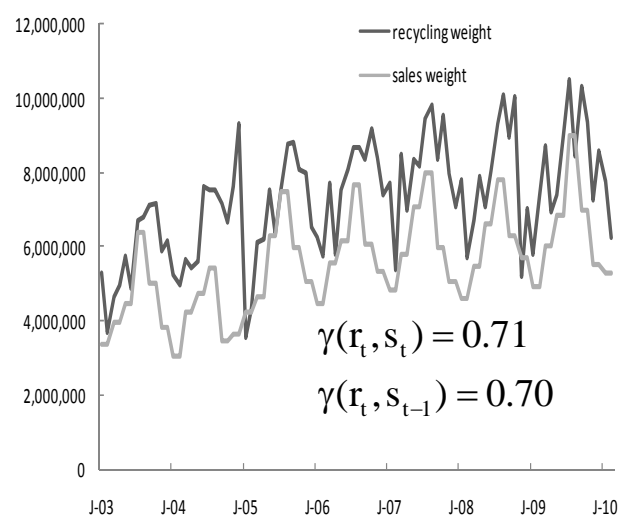

(a) The recycling and sales weights of DRW PET container (2003/1 2010/2)

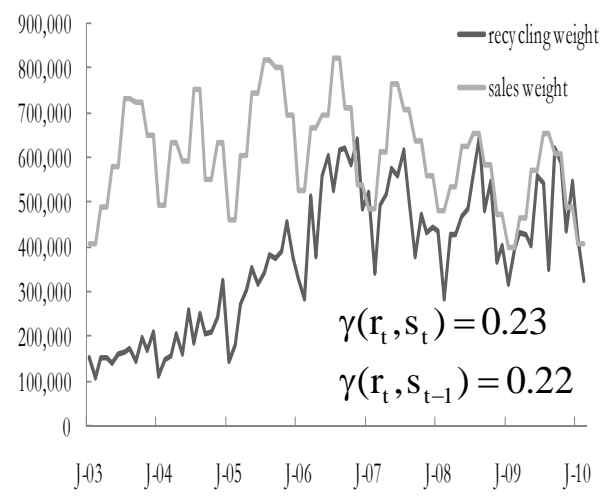

(c) The recycling and sales weights of DRW PS non-form container $(2003 / 1 \sim 2010 / 2)$

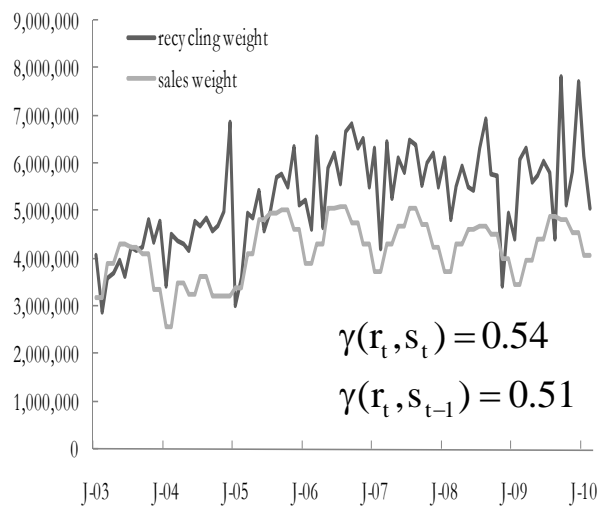

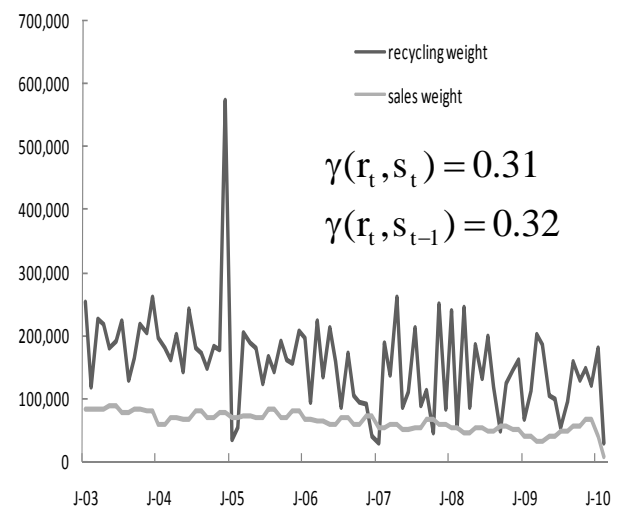

(b) The recycling and sales weights of DRW PVC container (2003/1 2010/2)

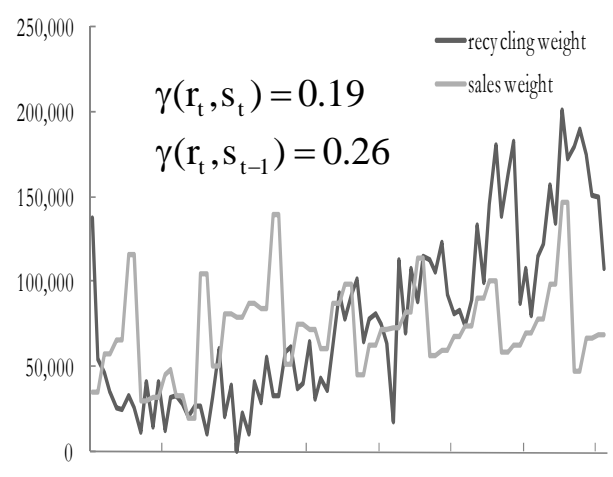

\begin{tabular}{llllllll}
\hline-03 & $J-04$ & $J-05$ & $J-06$ & $J-07$ & $j-08$ & $J-09$ & $J-10$
\end{tabular}

(d) The recycling and sales weights of DRW PS form container (2003/1 2010/2)

Note: The unit of $\mathrm{X}$-axis is monthly data, and the unit of $\mathrm{Y}$-axis is $\mathrm{kg}$.

(e) The recycling and sales weights of DRW PP/PE container $(2003 / 1 \sim 2010 / 2)$

Fig. (3). The recycling and sales weights and their correlation coefficient of Plastic DRWCs in Taiwan. Data source: this paper modified the data of RFMB.

distinguishable from those in most countries, perhaps due to the per-bag collection fee for general waste clearance and disposal and to the fact that the municipal garbage collection teams check the trash to retrieve recyclable resources in Taiwan and Japan.

Some problems still exist within the Four-in-One Program. For example, the price of recycled materials is much less than the total costs of the program. Additionally, there are increasing execution costs, supervision costs, social costs and risks of interruption of the recycling channels. [19] reviewed the recycling performance of the United States by looking at the inflation-adjusted cost of its recycling program, the rate of recycling participation and the amount of waste diverted from disposal by recycling in 1989 and 1996. [19] found that the price of recycled materials was 


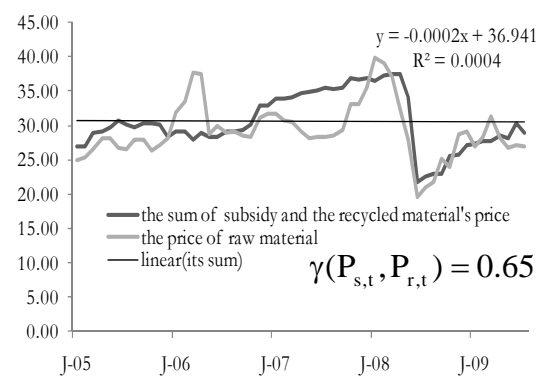

(a) The price of raw material and the recycled revenue by DRW PET container (2005/6 2009/12)

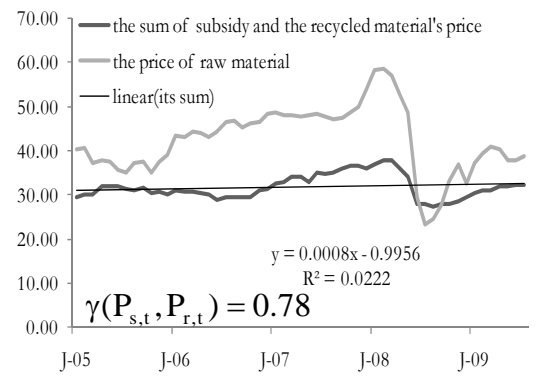

(c) The price of raw material and the recycled revenue by DRW PS non-form container (2005/6 $\sim 2009 / 12$ )

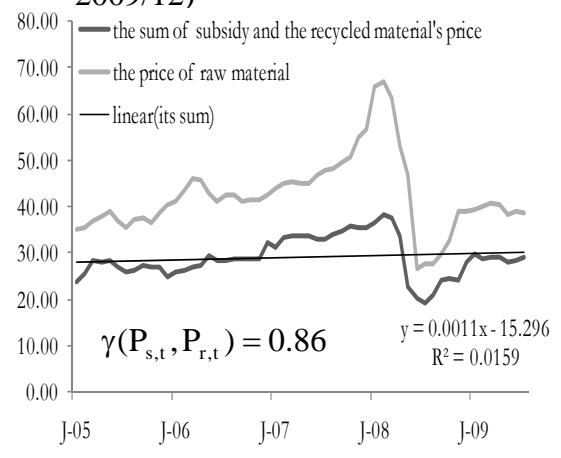

(e) The price of raw material and the recycled revenue by DRW PP/PE container (2005/6 2009/12)

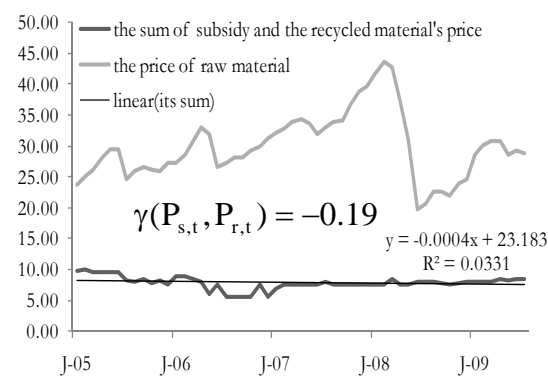

(b) The price of raw material and the recycled revenue by DRW PVC container (2005/6 2009/12)

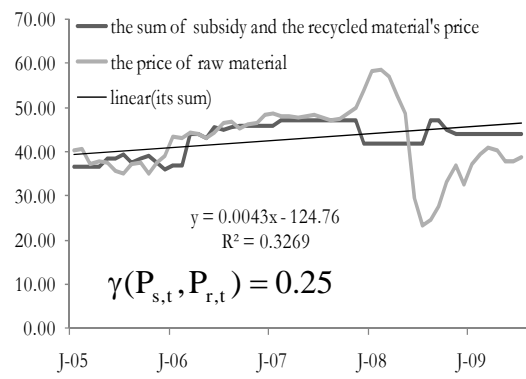

(d) The price of raw material and the recycled revenue by DRW PS form container (2005/6 2009/12)

Note: The unit of $\mathrm{X}$-axis is monthly data, and the unit of Y-axis is New

Taiwan dollar (NTD).

Fig. (4). The price of raw material and the recycled revenue by plastic DRWCs in Taiwan. Data source: this paper modified the data of RFMB.

approximately $35 \%$ of the total costs of its municipal recycling programs.

As DREs become more numerous, the execution costs, supervision costs and social costs are increasing with time, and DREs do not always consider the development of product design for recycling or reuse and recycling technologies. [20] suggest that manufacturers should be directly responsible for the development of recycling technologies and the design phase of notebooks. The number of DREs was increased almost 5.79 times by the government, from 2,775 in 1998 to 15,998 in 2009, while the number of entities in the recycling and treatment industries also increased almost 2.46 times, from 317 in 2002 to 781 in 2009.
The social costs stem from the fact that DREs tend to increase the magnitude or targets of RRFs, while the recycling and treatment industries instead argue for the increased magnitude or targets of subsidies. [20] analyze the Four-in-One Program by conducting a cost-benefit analysis and a formal life cycle assessment (LCA). They critique the current program for falling short of providing incentives for domestic recycling infrastructure and scarcely covering operating costs, which leaves little capital to develop new recycling technologies and fails to induce widespread consumer participation.

Prices of recycled DRW plastic containers vary greatly, as shown in Fig. (5). The recycling channels are at risk of interruption when recycling revenue is less than the cost of 


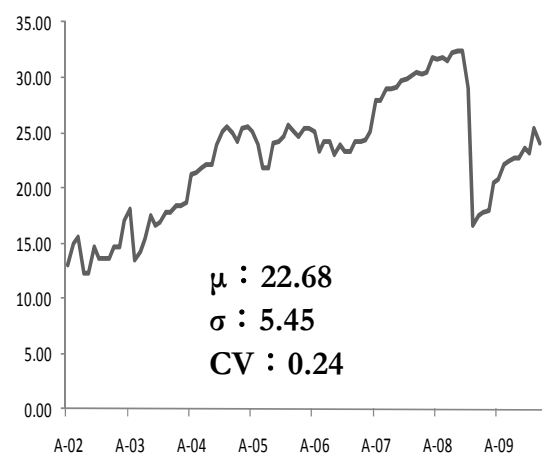

(a) The price of recycled material by DRW PET container (2002/4 2009/12)

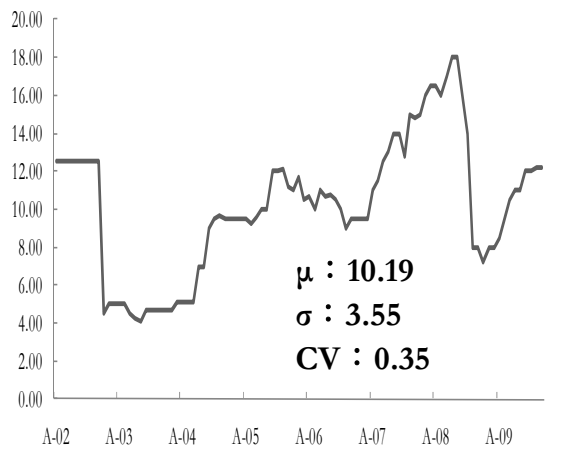

(c) The price of recycled material by DRW PS non-form container (2002/4 2009/12)

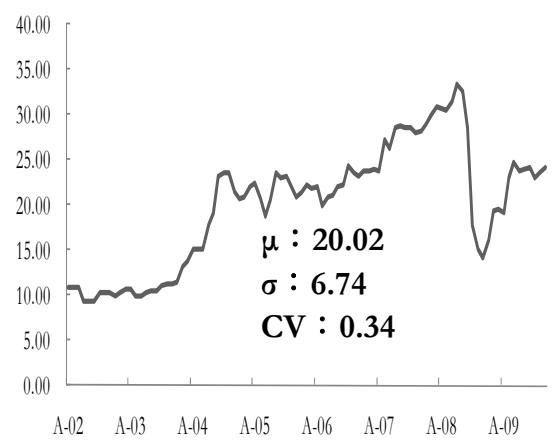

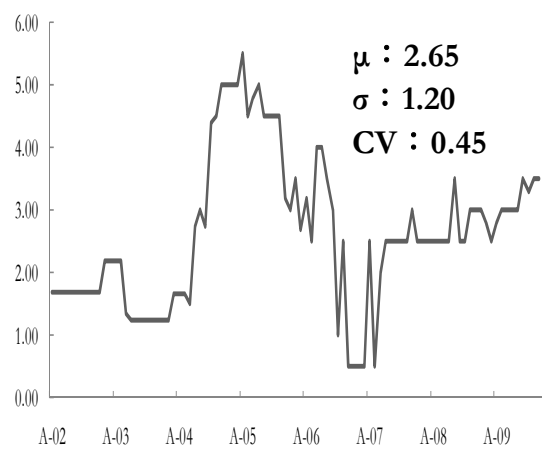

(b) The price of recycled material by DRW PVC container

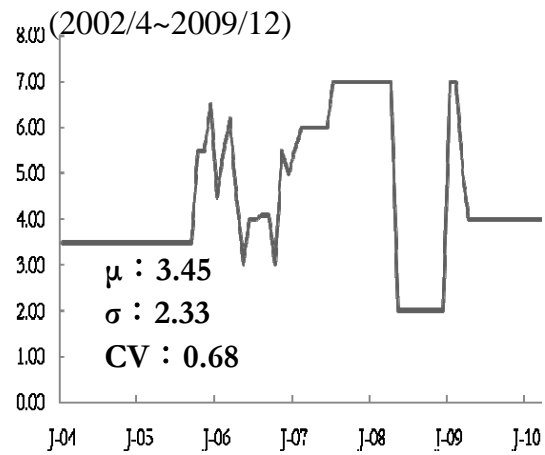

(d) The price of recycled material by DRW PS form container (2002/4 2009/12)

Note: The unit of $\mathrm{X}$-axis is monthly data, and the unit of $\mathrm{Y}$-axis is New Taiwan dollar (NTD).

(e) The price of recycled material by DRW PP/PE container (2002/4 2009/12)

Fig. (5). The mean and standard deviation of the price (NT\$) of 5 categories Plastic DRWCs' recycled material in Taiwan. Data Source: This paper modified the data of RFMB.

recycling and treatment (as shown by the trend line in Fig. 4). Fig. (4) also shows that recycling revenues are sometimes well below the trend lines, increasing the risk that the recycling channels might be shut down. The coefficients of variation for recycled material prices for DRW PET, PVC, PS non-form, PS form and PP/PE containers were 0.24, 0.45, $0.35,0.68$ and 0.34 , respectively in the period from 2002/4 2009/12 (the maximums were NT\$32.46 dollars $/ \mathrm{kg}$ in 2008/9, NT\$5.50 dollars $/ \mathrm{kg}$ in 2005/4, NT\$18.00 dollars $/ \mathrm{kg}$ in 2008/7 8, NT\$7.00 dollars/kg in 2007/7 12, 2008/1 4, 2009/1 2, and NT\$33.42 dollars/kg in 2008/7, respectively; the minimums were NT\$12.35 dollars $/ \mathrm{kg}$ in 2002/7 8, NT\$0.50 dollars/kg in 2006/12, 2007/1 3, 5, NT\$4.13 dollars/kg in 2003/8, NT\$2.00 dollars/kg in
2008/5 12, and NT\$9.34 dollars/kg in 2002/7 9, respectively).

Finally, the FRC, the ACSC and the TAC are organizations that assist the RFMB in the smooth operation of the Four-in-One Program. There is not a great deal of literature discussing their effectiveness in this regard, although there is still more work to be done on this issue.

\section{CONFLICT OF INTEREST}

The author confirms that this article content has no conflict of interest.

\section{ACKNOWLEDGEMENTS}

Declared none. 


\section{APPENDIX}

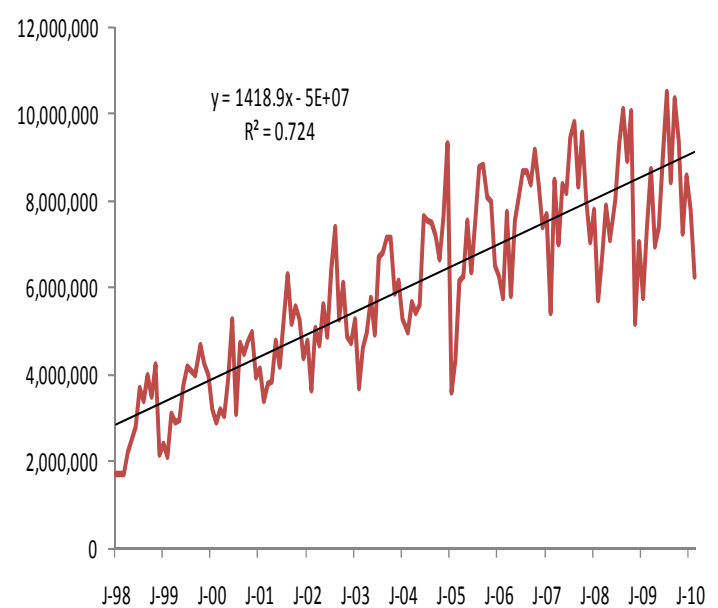

(a) The recycling weight of DRW PET container (1998/1 2010/2)

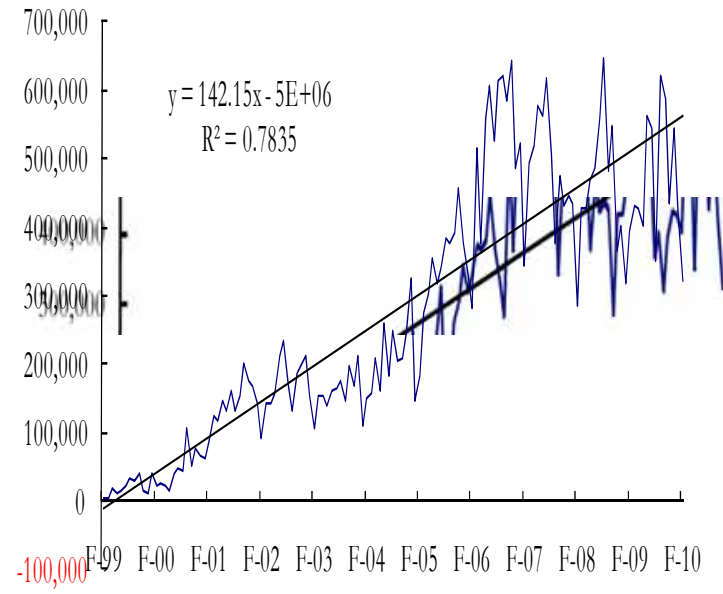

(c) The recycling weight of DRW PS non-form container (1998/1 2010/2)

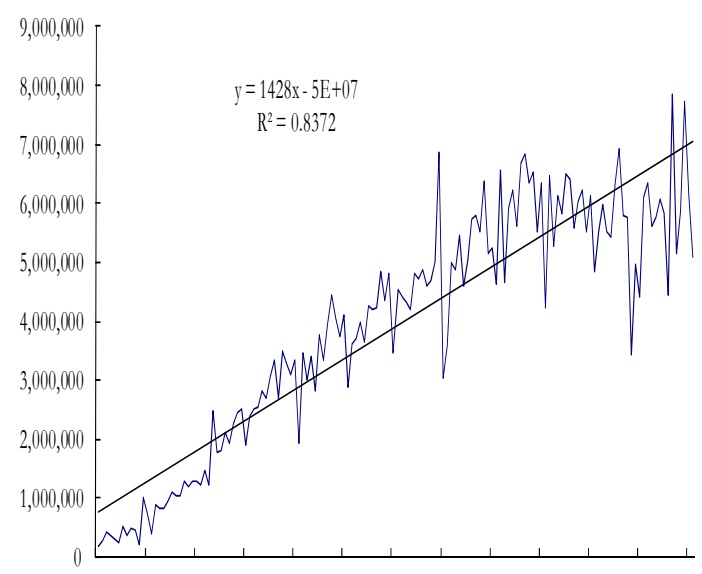

$\begin{array}{lllllllllllll}J-98 & J-99 & J-00 & J-01 & 5-02 & J-03 & J-04 & J-05 & J-06 & j-07 & J-08 & J-09 & J-10\end{array}$

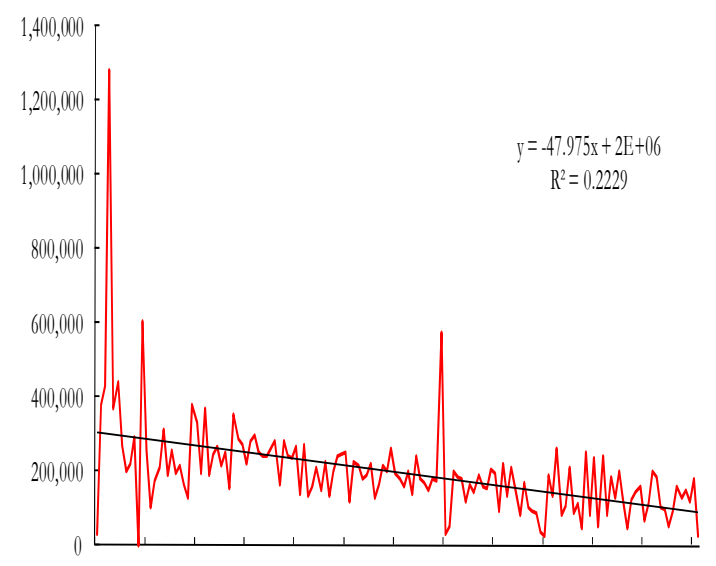

$\begin{array}{lllllllllllll}J-98 & J-99 & J-00 & J-01 & J-02 & J-03 & J-04 & J-05 & J-06 & J-07 & J-08 & J-09 & J-10\end{array}$

(b) The recycling weight of DRW PVC container (1998/1 2010/2)

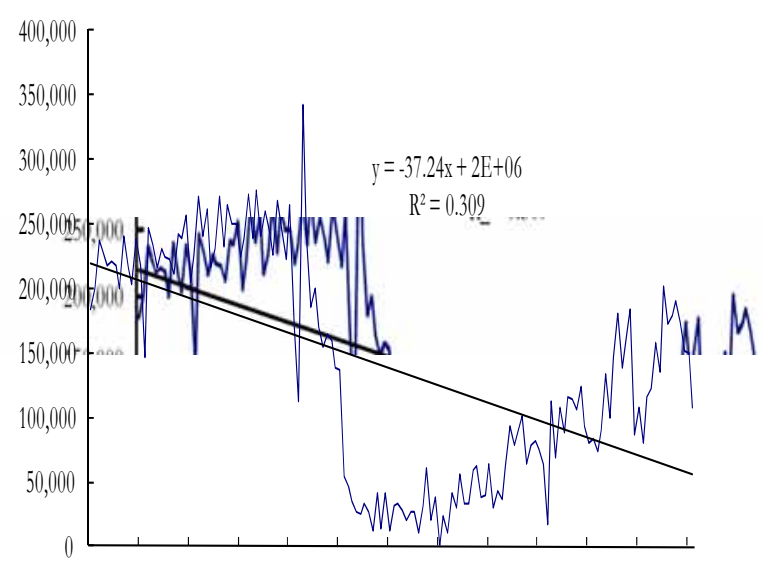

$\begin{array}{lllllllllllll}-098 & J-99 & J-00 & J-01 & J-02 & J-03 & J-04 & J-05 & J-06 & J-07 & J-08 & J-09 & J-10\end{array}$

(d) The recycling weight of DRW PS form container (1999/2 2010/2)

Note: The unit of $\mathrm{X}$-axis is monthly data, and the unit of $\mathrm{Y}$-axis is $\mathrm{kg}$.

(e) The recycling weight of DRW PP/PE non-form container (1998/1 2010/2)

Appendix Fig. (1). The recycling weight of plastic DRWCs in Taiwan. Data source: this paper modified the data of RFMB. 


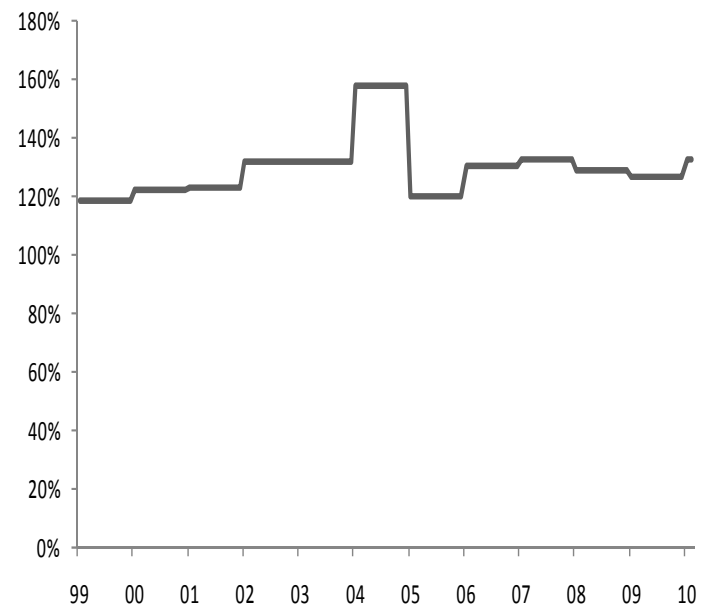

(a)The recycling rate of DRW PET container (1999 2010)

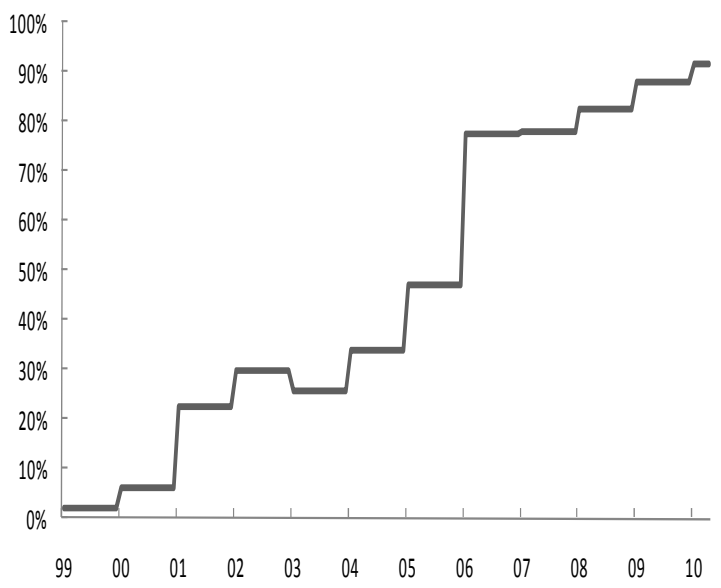

(c)The recycling rate of DRW PS non-form container (1999 2010)

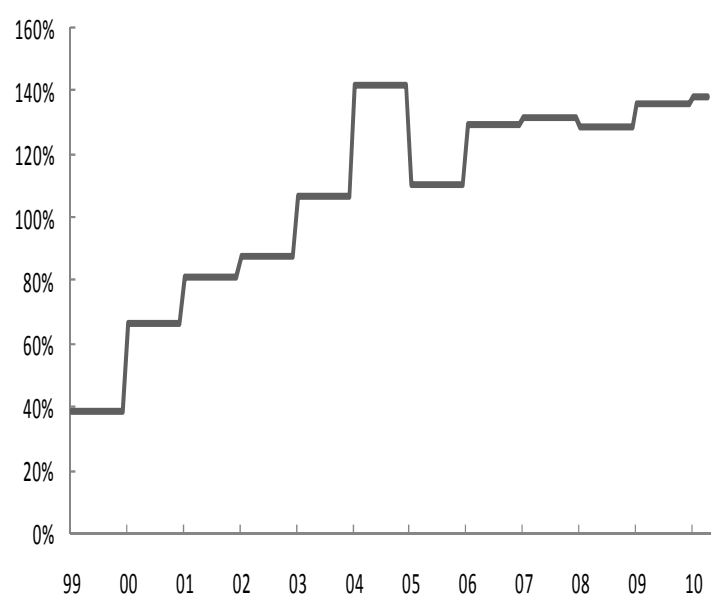

(c)The recycling rate of DRW PP/PE container (1999 2010)

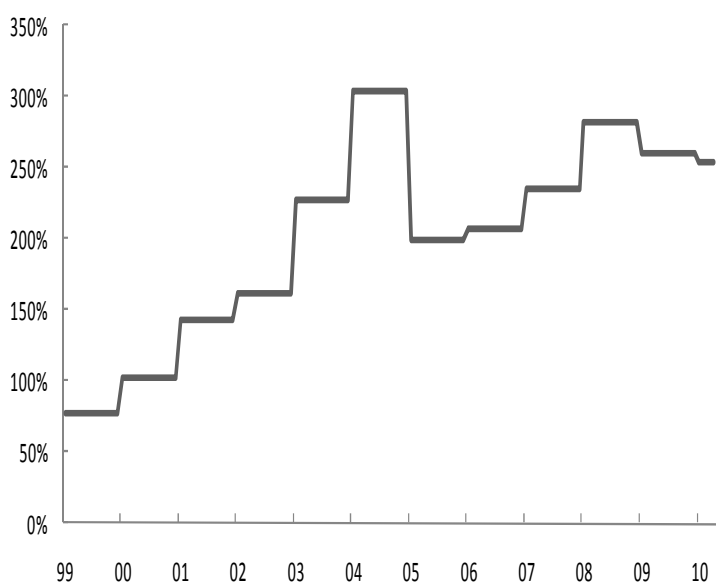

(b)The recycling rate of DRW PVC container (1999 2010)

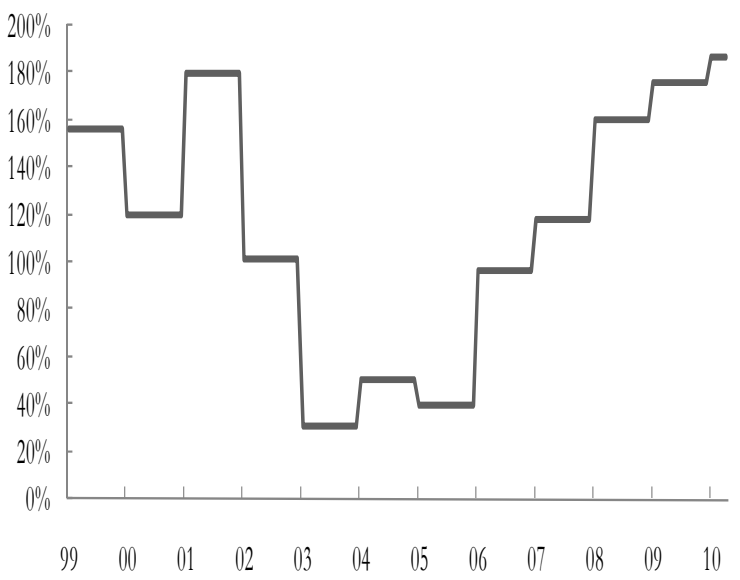

(d)The recycling rate of DRW PS form container (1999 2010)

Note: The unit of $\mathrm{X}$-axis is annual data, and the unit of $\mathrm{Y}$-axis is $\mathrm{kg}$.

Appendix Fig. (2). The recycling rate of plastic DRWCs in Taiwan. Data source: this paper modified the data of RFMB. 


\section{REFERENCES}

[1] Bor, YJ, Chien YL, Hsu E. The market-incentive recycling system for waste packaging containers in Taiwan. Environ Sci Policy 2004; 7(6): 509-23.

[2] EEA. Effectiveness of Packaging Waste Management Systems in Selected Countries: an EEA Pilot Study 2005.

[3] ETC/RWM. Waste Prevention, Waste Management and Landfill Policies Effectiveness. Outline of a Quantitative Analysis at European Level. ETC/ RWM working paper 10/2008, 2008.

[4] Suwa T, Usui T. Estimation of garbage reduction and recycling promotion under the containers and packaging recycling law and garbage pricing. Environ Econ Policy Studies 2007; 8(3): 239-54.

[5] Hsu E, Kuo CM. Recycling rates of waste home appliances in Taiwan. Waste Manage 2005; 25(1): 53-65.

[6] EEA. Diverting waste from landfill - Effectiveness of wastemanagement policies in the European Union 2009.

[7] ETC/RWM, Evaluation of waste policies related to the Landfill Directive, Italy, ETC/RWM working paper 8/2008, 2008

[8] Bridgwater AV. Refuse composition projections and recycling technology. Resour Conserv 1986; 12(3): 159-74.

[9] Sundin E, Svensson N, McLaren J, Jackson T. Materials and energy flow analysis of paper consumption in the United Kingdom, 1987-2010. J Industr Ecol 2001; 5(3): 89-105.

[10] OECD. OECD Environmental Outlook to 2030, 2008.
[11] Parent F, Vanacker L, Vandeputte A, Wille D. Municipal waste management in Flanders - Experience and Challenges, OVAM 2004

[12] Wille D. Economic instruments to steer eco-consumption involving local authorities in the Flemish Region, OVAM 2004.

[13] ETC/RWM. Evaluation of waste policies related to the Landfill Directive, The Flemish Region, ETC/ RWM working paper 5/2008. 2008.

[14] OVAM. Implementation Plan for Environmentally Responsible Household Waste Management, 2008

[15] ETC/RWM. Evaluation of waste policies related to the Landfill Directive, Germany, ETC/RWM working paper 6/2008, 2008.

[16] Ministry of Environment Government of Japan. State of discharge and treatment of municipal solid waste in FY2008, Government of Japan 2009.

[17] The Basic Act for Establishing a Sound Material-Cycle Society. Act No.110 of 2000, Japan 2000.

[18] Loughlin, DH, Barlaz MA. Policies for strengthening markets for recyclables: a worldwide perspective. Crit Rev Environ Sci Technol 2006; 36(4): 287-326.

[19] Folz DH. Municipal recycling performance: a public sector environmental success story. Public Admin Rev 1999; 59(4): 33643.

[20] Lu LT, Wernick IK, Yu TY, Hsiao YH, Yang YM, Ma HW. Balancing the life cycle impacts of notebook computers: Taiwan's experience. Resour Conserv Recy 2006; 48(1): 13-25.

(C) Wei-Lung Huang; Licensee Bentham Open.

This is an open access article licensed under the terms of the Creative Commons Attribution Non-Commercial License (http: //creativecommons.org/licenses/by$\mathrm{nc} / 3.0 /$ ) which permits unrestricted, non-commercial use, distribution and reproduction in any medium, provided the work is properly cited. 